\title{
Knowledge and Practice on Tuberculosis among Prison Workers from Seremban Prison
}

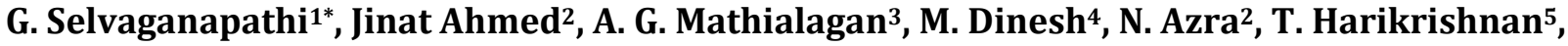 \\ S. Vanita6, M. N. M. Nazmul'2, Agus Iwan Foead ${ }^{3}$
}

\author{
${ }^{1}$ Seremban Prison, Malaysian Prison Department, Home Ministry, Putrajaya, Malaysia \\ ${ }^{2}$ Perdana University Graduate School of Medicine, Perdana, Malaysia \\ ${ }^{3}$ Perdana University Royal College of Surgeons Ireland, Serdang, Malaysia \\ ${ }^{4}$ SP Care Group, Health Care, Rawang, Malaysia \\ ${ }^{5}$ Department of Rehabilitation Medicine, Hospital Tunku Ampuan Rahimah, Klang, Malaysia \\ ${ }^{6}$ Klinik Sri Pulai Sdn Bhd, Seremban, Malaysia \\ Email: *selvaganapathiganeson@yahoo.com
}

How to cite this paper: Selvaganapathi, G., Ahmed, J., Mathialagan, A.G., Dinesh, M., Azra, N., Harikrishnan, T., Vanita, S., Nazmul, M.N.M. and Foead, A.I. (2019) Knowledge and Practice on Tuberculosis among Prison Workers from Seremban Prison. Occupational Diseases and Environmental Medicine, 7, 176-186.

https://doi.org/10.4236/odem.2019.74014

Received: September 10, 2019

Accepted: October 29, 2019

Published: November 1, 2019

Copyright () 2019 by author(s) and Scientific Research Publishing Inc. This work is licensed under the Creative Commons Attribution International License (CC BY 4.0).

http://creativecommons.org/licenses/by/4.0/

Open Access

\begin{abstract}
Background: Prisons are always overcrowded, and congestion leads to close relationships, and subsequently, increases the likelihood of airborne illnesses including Tuberculosis (TB). The purpose of this study was to identify the level of knowledge of TB transmission, and TB preventive practices of prison workers in a Malaysian prison. Methods: A cross-sectional study was conducted with convenience sampling technique utilizing a validated questionnaire. 280 prison workers employed at the Seremban Prison were invited to participate in the study. The study period was from January 2019 to June 2019. Inclusion criteria included age above 18 years old and English literacy. The questionnaire was divided into 3 parts which were sociodemographic details, knowledge on TB transmission and TB preventive practices. The analysis was done in SPSS version 24.0 using appropriate statistical tests. Descriptive statistics was used to evaluate the knowledge level of TB transmission, and TB preventive practices of prison workers at Seremban prison. Results: Around 190 questionnaires were obtained usable registering a response rate of $68.5 \%$. This study showed that around $66 \%$ of prison workers had moderate knowledge while around $26 \%$ had good knowledge of TB transmission. In terms of practice, around $93.7 \%$ of prison workers applied good TB prevention practice. Conclusion: This study showed that the majority of the respondents had moderate knowledge regarding TB transmission. However, their disease preventive practices were at acceptable levels which implied that existing prison standard operating procedures play an important on instilling these practices. Nonetheless, prison management should take important ac-
\end{abstract}


tion by providing education and training to increase TB knowledge among prison workers to ensure that this practice is always upheld in both prison and community settings.

\section{Keywords}

Knowledge, Practice, Prevention, Tuberculosis, Prison Worker, Prison, Malaysia

\section{Introduction}

Tuberculosis (TB) is one of the most common worldwide infectious diseases and one of the leading causes of death in the world, with an overall 1.7 million TB-related deaths reported in 2016, despite accessibility of TB treatment. In 2016, the World Health Organization (WHO) estimated a total of 10.4 million incident $\mathrm{TB}$ cases globally, $10 \%$ of whom were living with HIV infection. The burden of TB is the highest in the South-East Asian and African regions, which accounted for $70 \%$ of the global TB incidence in 2016 [1]. In fact, since 1993, TB has been declared as a "global emergency" by the World Health Organization until now [2] [3].

In Malaysia, TB is the second most frequently reported communicable disease (after dengue fever) and is the leading cause of death from communicable diseases, with a mortality rate of 5.56 per 100,000 persons [4]. In 2017(5), estimated TB burden by Malaysia per 1,000,000 for mortality (HIV \& TB only) was 0.93 and incidence (HIV \& TB) was 5.7. By gender estimate, TB incidence in Malaysia has shown male (18 cases per 1,000,000) at higher levels than female (11 case per 100,000). A number of cases registered and notified as TB cases in 2017 account for around 26,168 cases. Malaysia has witnessed an increase in the incidence of TB, from 65 cases per 100,000 in 2000 to 92 per 100,000 in 2016 by the global TB report [5].

Closed settings, including prisons, present special challenges to national TB control programs. Prisons are concentrated populations of individuals at high risk of TB, such as people who use drugs and/or alcohol, the homeless, people with a history of past incarceration, and people with pre-existing comorbidities. Poor environmental conditions, such as overcrowding and inadequate ventilation, and restricted access to health care services can facilitate the transmission of TB in prisons [6], [7]. The prevalence of TB is estimated to be up to 100 times higher in prisons than in the general populations [8], [9]. Recent reports from 2 Malaysian prisons have shown a very high ( $>80 \%)$ prevalence of latent TB infection among prisoners, irrespective of HIV status. A follow-up intensified case-finding survey in one of these prisons reported a high prevalence $(7.7 \%)$ of previously undiagnosed active TB [10]. This prison is overcrowded and has a daily census of 4200 prisoners, operating at $120 \%$ of its maximum capacity of 3500 [11]. 
The high burden of TB within prison poses a threat to the general population, as the disease can be transmitted to correctional staff who are in daily close contact with prisoners. Furthermore, inmates who are incarcerated for a short period of time and who do not receive adequate treatment may transmit the disease on their return to the community [12]. In a recent systematic review, a large fraction of TB cases in the general population was attributable to acquisition of TB inside prison. This has been estimated at 1 in $11 \mathrm{~TB}$ cases in high-income countries and 1 in 16 cases in low-/middle-income countries. Another study estimated that for each $1 \%$ increase in the incarceration rate in European and Central Asian countries, there was a $0.34 \%$ increase in TB incidence in the general population [13].

Despite recent findings of high prevalence rates of both latent and active TB in Malaysian prisons, routine intensified TB screening and treatment are not currently practiced, and diagnosis of active TB remains passive. Environmental conditions, such as overcrowding and poor ventilation, further facilitate the transmission and spread of TB in these settings. To counter these precipitating factors for TB transmission, it is important that prison workers have good knowledge on TB transmission and apply excellent preventive practices associated with $\mathrm{TB}$ diseases to ensure low risk of $\mathrm{TB}$ incidence among prison workers. However, there has been minimal studies evaluating TB knowledge and practice on prison workers in Malaysia. So this study undertook the objective of determine the level of TB transmission knowledge and TB preventive practices among prison workers in a selected prison in Malaysia.

\section{Materials and Methods}

This cross-sectional study was conducted in Seremban Prison in Malaysia from January 2019 to June 2019. Seremban Prison was selected because it was one of the oldest prisons in Malaysia and it functions also as a prison for drug abuse offenders. The study population was full-time Seremban prison workers such as correctional officers which included all the ranks from the Prison Wardens up to Assistant Commissioner of Prisons (KA 48), healthcare personnel and administrative staff. The sample size was calculated and the required sample size was 162 respondents with a $95 \%$ confidence level. Convenience sampling was used due to the restriction in time, place, and logistics. The inclusion Criteriawere: 1) The respondent was required to be above 18 years old. 2) The respondent could read, write and speak English. iii. The respondent was willing to participate. The questionnaires were distributed using convenience sampling to all the prison employees who met the inclusion criteria. The participants were given a brief explanation of the study and required to fill up the consent form before answering the questionnaires.

The questionnaire attached in Appendix 1, consists of 4 main sections and a total of 32 items. This structure of the items involved closed ended questions such as dichotomous (yes/no) and a Likert scale-based agree/disagree component. The study questionnaire was adapted from a similar study done in Ethiopia 
which evaluated TB knowledge on prison workers and prisoners [14]. The Ethiopian study developed the questionnaire based on the general guidelines of WHO KAP questionnaires design and adapted to suit TB KAP exploration with evaluation on factor analysis and reliability [15]. For the purpose of our study, we undertook the responsibility to additionally re-evaluate content validity and face validity. The validity findings of our study were consistent with the earlier study and a pilot test by 30 respondents gave a similar average Cronbach alpha value of 0.887 , confirming adequate reliability. This finalized version was used for data collection in the general sample population.

Data analysis was done using 'Statistical Package for Social Sciences' (SPSS) Version 22.0. The descriptive tests were computed using this software. The research proposal was reviewed and cleared by the Ethics Committee of Perdana University. Informed consent was obtained from each study subject.

\section{Results}

This chapter describes the characteristics of the study sample's knowledge, attitude and practice among prisoner workers on TB disease. Between January, 2019 to Jun 2019 at Seremban Prison, Seremban Negeri Sembilan, 280 questionnaires were given out to all prison workers which include all gender and position (uniform and administrative department) and around 190 questionnaires were returned usable for the study. This gave a response rate of $68.5 \%$.

\subsection{Socio-Demographic Variables among Respondents}

The sociodemographic profile of the current study respondents has been depicted in Table 1. The respondents' age distribution was $21-30$ [19.5\% ( $\mathrm{n}=$ 37)], $31-40$ [49.5\% $(\mathrm{n}=94)], 41-50[21 \%(\mathrm{n}=40)]$, and $\geq 50[10 \%(\mathrm{n}=19)]$ years old. The distribution of sexes among the respondents was $86.3 \%(n=164)$ and $13.7 \%(n=26)$ for males and females respectively. The distribution of the respondents' ethnicity was Malay [94.2\% $(n=179)]$, Indian [2.6\% $(n=5)]$ and others $[3.2 \%(n=6)]$. The pattern of the respondents' martial was single $[9.5 \%$ $(\mathrm{n}=18)]$, married [88.4\% (168)] and discover/window [2.1\% $(\mathrm{n}=4)]$. Considering the respondents' educational level, $[61.1 \%(\mathrm{n}=116)]$ had primary/secondary education, and $[38.9 \%(n=74)]$ had university/college education. The respondents' period of services was $11-20$ years [37.9\% $(n=72)], 2$ 10 years $[35.3 \%(n=67)], 21-30$ years $[15.3 \%(n=29)]$, more than 30 years $[5.2 \%(n=10)]$, and less than 1 years $[6.3 \%(n=12)] .[82.1 \%(n=156)]$ of the respondents lived $0-10 \mathrm{~km},[15.3 \%(\mathrm{n}=29)]$ lived in $11-20 \mathrm{~km},[1.6 \%(\mathrm{n}=3)]$ lived in $21-30 \mathrm{~km}$ and $[1 \%(\mathrm{n}=2)]$ other respondents more than $30 \mathrm{~km}$. The distribution of the respondents' previous history of TB, [83\% $(n=83)]$ were not been diagnosis, and $[93.2 \%(n=177)]$ were been diagnosis.

\subsection{Knowledge about Tuberculosis (TB)}

The level of knowledge among the respondents regarding TB was determined by generating the score from the descriptive analysis to classify them into "Good 
Table 1. Respondents demographic data $(\mathrm{N}=190)$.

\begin{tabular}{|c|c|c|c|c|}
\hline No. & Main category & Sub-category & Sample (n) & Percentage \% \\
\hline \multirow{4}{*}{1.} & \multirow{4}{*}{ Age } & $21-30$ & 37 & 19.5 \\
\hline & & $31-40$ & 94 & 49.5 \\
\hline & & $41-50$ & 40 & 21 \\
\hline & & $\geq 51$ & 19 & 10 \\
\hline \multirow{2}{*}{2.} & \multirow{2}{*}{ Gender } & Male & 164 & 86.3 \\
\hline & & Female & 26 & 13.7 \\
\hline \multirow{4}{*}{3.} & \multirow{4}{*}{ Race } & Malay & 179 & 94.2 \\
\hline & & Indian & 5 & 2.6 \\
\hline & & Chinese & 0 & 0 \\
\hline & & Others & 6 & 3.2 \\
\hline \multirow{3}{*}{4.} & \multirow{3}{*}{ Marital status } & Single & 18 & 9.5 \\
\hline & & Married & 168 & 88.4 \\
\hline & & Divorced/window & 4 & 2.1 \\
\hline \multirow{3}{*}{5.} & \multirow{3}{*}{ Education level } & No formal education & 0 & 0 \\
\hline & & Primary/Secondary School & 116 & 61.1 \\
\hline & & College/University & 74 & 38.9 \\
\hline \multirow{5}{*}{6.} & \multirow{5}{*}{$\begin{array}{l}\text { Period of Service } \\
\text { in prison }\end{array}$} & Under 1 year & 12 & 6.3 \\
\hline & & $2-10$ years & 67 & 35.3 \\
\hline & & $11-20$ years & 72 & 37.9 \\
\hline & & 21 - 30 years & 29 & 15.3 \\
\hline & & $\geq 30$ years & 10 & 5.2 \\
\hline \multirow{4}{*}{7.} & \multirow{4}{*}{ Distance of healthcare } & $0-10 \mathrm{~km}$ & 156 & 82.1 \\
\hline & & $11-20 \mathrm{~km}$ & 29 & 15.3 \\
\hline & & $21-30 \mathrm{~km}$ & 3 & 1.6 \\
\hline & & $\geq 30 \mathrm{~km}$ & 2 & 1 \\
\hline \multirow{2}{*}{8.} & Previous or & Yes & 13 & 6.8 \\
\hline & current TB treatment & No & 177 & 93.2 \\
\hline
\end{tabular}

Knowledge", "Moderate Knowledge" and "Poor Knowledge". Hence, a respondent who able to answer 7 questions and above were considered to have good knowledge, whereas those who able to answer around $4-6$ questions were moderate knowledge. Those respondents who were able to answer less than 4 questions were considered to have poor knowledge. As shown in Table 2, many of the respondents had moderate knowledge which accounted for $66.3 \%(n=126)$, good knowledge was $26.3 \%(n=50)$ and only $7.4 \%(n=14)$ had poor knowledge regarding the topic. In terms of specific question analysis as shown in Table 3, majority of respondent's response was inaccurate for source of information for correct TB data with wrong answers accumulating to around $86.3 \%$ 
Table 2. Overall knowledge on TB level among prison workers $(n=190)$.

\begin{tabular}{ccccc}
\hline No. & Main Category & Sub-category & Sample (n) & Percentage (\%) \\
\hline \multirow{3}{*}{1.} & Koor & 14 & 7.4 \\
& Knowledge & Moderate & 126 & 66.3 \\
& & Good & 50 & 26.3 \\
\hline
\end{tabular}

Table 3. Knowledge of TB among the prison workers.

\begin{tabular}{|c|c|c|c|c|}
\hline No. & Questionnaire & Scoring & Sample (n) & Percentage (\%) \\
\hline \multirow[b]{2}{*}{1.} & \multirow{2}{*}{ Source of information } & Correct & 26 & 13.7 \\
\hline & & Wrong & 164 & 86.3 \\
\hline \multirow{2}{*}{2.} & Transmission risk of & Correct & 161 & 84.7 \\
\hline & $\mathrm{TB}$ in general population & Wrong & 29 & 15.3 \\
\hline \multirow{2}{*}{3.} & \multirow{2}{*}{ Transmission risk of TB in prison } & Correct & 99 & 52.1 \\
\hline & & Wrong & 91 & 47.9 \\
\hline \multirow{2}{*}{4.} & \multirow{2}{*}{ Symptom of TB } & Correct & 39 & 20.5 \\
\hline & & Wrong & 151 & 79.5 \\
\hline \multirow{2}{*}{5.} & \multirow{2}{*}{ Mode of Transmission } & Correct & 114 & 60 \\
\hline & & Wrong & 76 & 40 \\
\hline \multirow[b]{2}{*}{6.} & \multirow{2}{*}{ Who can contract TB } & Correct & 164 & 86.3 \\
\hline & & Wrong & 26 & 13.7 \\
\hline \multirow{2}{*}{7.} & \multirow{2}{*}{ Curability of TB } & Correct & 184 & 96.8 \\
\hline & & Wrong & 6 & 3.2 \\
\hline \multirow{2}{*}{8.} & \multirow{2}{*}{ TB treatment options } & Correct & 162 & 85.3 \\
\hline & & Wrong & 28 & 14.7 \\
\hline \multirow{2}{*}{9.} & Any law presents & Correct & 114 & 60 \\
\hline & related to TB disease & Wrong & 76 & 40 \\
\hline
\end{tabular}

$(\mathrm{n}=164)$ compared with only a small number of correct answers $13.7 \%(\mathrm{n}=26)$. Most of the respondent were not able to identify all the symptoms of TB [79.5\% $(\mathrm{n}=151)]$ compared to the minority with correct answers $[20.5 \%(\mathrm{n}=39)]$. However, respondents were able to give correct answer to some important questions in regards to mode of transmission $60 \%(\mathrm{n}=114)$, high risk to be contact with TB $86.3 \%(\mathrm{n}=143)$, TB curability $96.8 \%(\mathrm{n}=184)$ and treatment options for TB around $85.3 \%(n=162)$.

\subsection{Prevention Practice on TB}

The level of prevention practice among the respondents regarding TB was determined by generating the score from the descriptive analysis to classify them into "Good practice" and "Poor practice". Hence, a respondent who scored 20 marks and above were considered to have good practice, whereas those who 
scored less than 20 marks were considered to have poor practice. As shown in Table 4, many of the respondents had good knowledge which accounted for $93.7 \%(\mathrm{n}=178)$, and only $6.3 \%(\mathrm{n}=12)$ had poor knowledge regarding the topic. In terms of specific question analysis as shown in Table 5, majority respondents did answered questions such as covering mouth when coughing or sneezing with strongly agreement of 60.5. Similarly, most respondents had strong awareness on the importance of hand washing methods with more than $80 \%$ in agreement. The pattern showed respondents supported statement for isolating patient if present with TB. Almost all the respondent's response for sufficient ventilation was in strong agreement ranging from $66.8 \%$ and agreement at $30 \%$. Majority of respondents also supported regular sputum examination with strong agreement around $70 \%$ and agreement $25.8 \%$.

\section{Discussion}

The purpose of this study was to examine the knowledge level and prevention practice on TB among prison workers in Seremban Prison. The study indicated that high proportions of respondent had moderate knowledge of TB transmission. However, most of the respondents exhibited good practice level in terms of TB prevention. The findings differ slightly from another local study done in Tapah prison in Malaysia which showed good knowledge and good practice among prison workers [16]. Another study done in Brazil which compared knowledge of prison workers, prisoners and public health workers found that there was very good knowledge, attitude and practice among prison workers and public health workers but low knowledge and practice among prisoners [17].

Table 4. Overall prevention practice level among prison workers $(n=190)$.

\begin{tabular}{|c|c|c|c|c|}
\hline No. & Main category & Sub category & Sample (n) & Percentage (\%) \\
\hline \multirow{2}{*}{1.} & & Good & 178 & 93.7 \\
\hline & 1 1actec & Poor & 12 & 6.3 \\
\hline
\end{tabular}

Table 5. Descriptive of prevention practice $(n=190)$.

\begin{tabular}{|c|c|c|c|c|c|c|c|c|c|c|c|}
\hline \multirow{2}{*}{ No. } & \multirow{2}{*}{ Item } & \multicolumn{2}{|c|}{$\begin{array}{l}\text { Strongly } \\
\text { disagree }\end{array}$} & \multicolumn{2}{|c|}{ Disagree } & \multicolumn{2}{|c|}{ Uncertain } & \multicolumn{2}{|c|}{ Agree } & \multicolumn{2}{|c|}{$\begin{array}{l}\text { Strongly } \\
\text { agree }\end{array}$} \\
\hline & & $\mathrm{n}$ & $\%$ & $\mathrm{n}$ & $\%$ & $\mathrm{n}$ & $\%$ & $\mathrm{n}$ & $\%$ & $\mathrm{n}$ & $\%$ \\
\hline 1. & $\begin{array}{c}\text { Cover mouth } \\
\text { when cough/sneezing }\end{array}$ & 1 & 0.5 & 3 & 1.6 & 0 & 0 & 71 & 37.4 & 115 & 60.5 \\
\hline 2. & $\begin{array}{l}\text { Washing } \\
\text { hand }\end{array}$ & 1 & 0.5 & 1 & 0.5 & 3 & 1.6 & 72 & 37.9 & 113 & 59.5 \\
\hline 3. & $\begin{array}{l}\text { Isolating } \\
\text { TB patients }\end{array}$ & 1 & 0.5 & 4 & 2.1 & 7 & 3.7 & 41 & 21.6 & 137 & 72.1 \\
\hline 4. & $\begin{array}{l}\text { Sufficient } \\
\text { ventilation }\end{array}$ & 1 & 0.5 & 0 & 0 & 5 & 2.6 & 57 & 30 & 127 & 66.8 \\
\hline 5. & $\begin{array}{l}\text { Regular sputum } \\
\text { examination }\end{array}$ & 1 & 0.5 & 0 & 0 & 7 & 3.7 & 49 & 25.8 & 133 & 70 \\
\hline
\end{tabular}


The differences with the above studies could be due to a number of factors in this study. Moderate knowledge among prison workers could be due to inadequate training and health education. Dengue is a major concern in Malaysia as it is the leading cause of death due to communicable diseases. Huge resources and budget have been allocated for dengue management to create awareness and preventive health education [18], [19]. Unfortunately, the same emphasis was not given to tuberculosis prevention, particularly in high risk areas such as prisons. Under National Strategic Plan for Tuberculosis Control (NSPT) (2016-2020), there was a consensus about prisons as a major source of TB transmission to general population and the need to strengthen preventive measures on these institutions. However, the implementation of major initiative was impacted due to the reduced budget capacity caused by volatility in oil prices [20]. Additionally respondents had not received any training in the previous year nor undertaken any TB health education course which would have improved their knowledge levels [21], [22]. The findings of the study identify the pressing need for TB training for all prison workers. The participants did not seem to fully comprehend the real risk of TB exposure, and most were afraid of becoming infected with TB. Concerns and stigma related to TB emerged particularly among prison workers from prison without $\mathrm{TB}$ related training. Irrational work practices and fear might lead to a higher risk of exposure [23].

Interestingly although prison workers had moderate level of knowledge on TB transmission but they had good preventive practice at their occupational setting. This could be due to the standard operating procedures (SOP) in place for TB disease prevention as required by law for prison settings under a country [24], [25]. Based on Malaysian law, any government or non-government agencies should obey or comply to Occupational Safety and Health Act 1994 (OSHA 1994) whereby institutions have a duty of care towards their employees safety and health, and to that of others at their workplace [26], [27], [28]. Among the guidelines present that prison workers should follow are Guideline for workplace the control of Tuberculosis and Ministry of Health Malaysia guideline for control of TB and a customized guideline for prisons that was developed as a collaborative effort by Ministry of Health and Department of Prison Malaysia [29], [30]. Major role for this policy or SOP for employees or employers is to protect fundamental rights and ensure them following the rule in order to protect the staff's safety and health. Frequent monitoring and auditing by internal and external management have also ensured the prison workers follow the policy or SOP which subsequently has ensured the practice is maintained at excellent standards [31], [32], [33].

\section{Conclusion}

Since the study showed that prison workers had moderate knowledge but good preventive practices, we can therefore conclude there were low chances for spread of TB to general population from prison population due to strict adher- 
ence to existing SOP's in prison. However, the moderate knowledge implies that the prison workers do not understand the importance of TB transmission and prevention, hence these practices may not be practiced at community levels. So, an important finding of this study is to increase educational intervention and knowledge empowerment of prison workers in prisons in Malaysia.

\section{Limitation}

One of the main limitations of this study would be its sample population. The study population was small and was limited to a cohort of prison staff in Seremban prison only, therefore the results of the study will not be generalized to all prison staff on knowledge, attitude and practice on tuberculosis in part of Negeri Sembilan or Malaysia prison as the situation in other districts may differ from what prevails in Seremban prison. Additionally, convenience sampling was administered rather than random sampling which would have given a stronger generalizability.

\section{Conflicts of Interest}

The authors declare no conflicts of interest regarding the publication of this paper.

\section{References}

[1] WHO (2017) Global Tuberculosis Report 2017.

[2] World Health Organization, Tuberculosis Unit (1994) Tuberculosis Notification Update, December 1993. World Health Organization.

[3] Daniel, T.M. (2006) The History of Tuberculosis. Respiratory Medicine, 100, 1862-1870. https://doi.org/10.1016/j.rmed.2006.08.006

[4] Thomas, S., Beh, L. and Nordin, R.B. (2011) Health Care Delivery in Malaysia: Changes, Challenges and Champions. Journal of Public Health in Africa, 2, e23. https://doi.org/10.4081/jphia.2011.e23

[5] Reports. https://extranet.who.int/sree/Reports?op=Replet\&name=/WHO_HQ Reports/G2/P $\underline{\text { ROD} / E X T / T B C o u n t r y P r o f i l e \& I S O 2=m y \& o u t t y p e ~}=$ pdf

[6] Baussano, I., Williams, B.G., Nunn, P., Beggiato, M., Fedeli, U. and Scano, F. (2010) Tuberculosis Incidence in Prisons: A Systematic Review. PLoS Medicine, 7, e1000381. https://doi.org/10.1371/journal.pmed.1000381

[7] Anderson, C., Story, A., Brown, T., Drobniewski, F. and Abubakar, I. (2010) Tuberculosis in UK Prisoners: A Challenge for Control. Journal of Epidemiology \& Community Health, 64, 373-376. https://doi.org/10.1136/jech.2009.094375

[8] Al-Darraji, H.A.A., Tan, C., Kamarulzaman, A. and Altice, F.L. (2015) Prevalence and Correlates of Latent Tuberculosis Infection among Employees of a High Security Prison in Malaysia. Occupational and Environmental Medicine, 72, 442-447. https://doi.org/10.1136/oemed-2014-102695

[9] Maher, D., Grzemska, M., Coninx, R. and Reyes, H. (1998) Guidelines for the Control of Tuberculosis in Prisons. 90.

[10] Abed Al-Darraji, H.A., Altice, F.L. and Kamarulzaman, A. (2016) Undiagnosed 
Pulmonary Tuberculosis among Prisoners in Malaysia: An Overlooked Risk for Tuberculosis in the Community. Tropical Medicine \& International Health, 21, 1049-1058. https://onlinelibrary.wiley.com/doi/full/10.1111/tmi.12726

[11] Al-Darraji, H.A.A., Kamarulzaman, A. and Altice, F.L. (2014) Latent Tuberculosis Infection in a Malaysian Prison: Implications for a Comprehensive Integrated Control Program in Prisons. BMC Public Health, 14, 22.

https://doi.org/10.1186/1471-2458-14-22

http://bmcpublichealth.biomedcentral.com/articles/10.1186/1471-2458-14-22

[12] The PLoS Medicine Editors (2010) The Health Crisis of Tuberculosis in Prisons Extends beyond the Prison Walls. PLoS Medicine, 7, e1000383.

https://doi.org/10.1371/journal.pmed.1000383

[13] Stuckler, D., Basu, S., Mckee, M. and King, L. (2008) Mass Incarceration Can Explain Population Increases in TB and Multidrug-Resistant TB in European and Central Asian Countries. Proceedings of the National Academy of Sciences of the United States of America, 105, 13280-13285.

https://www.researchgate.net/publication/23194885 Mass incarceration can expla in population increases in $\mathrm{TB}$ and multidrug-resistant $\mathrm{TB}$ in European and $\mathrm{c}$ entral Asian countries

[14] Adane, K., Spigt, M., Johanna, L., Noortje, D., Abera, S.F. and Dinant, G.-J. (2017) Tuberculosis Knowledge, Attitudes, and Practices among Northern Ethiopian Prisoners: Implications for TB Control Efforts. PLOS ONE, 12, e0174692.

https://doi.org/10.1371/journal.pone.0174692

[15] Stop TB Partnership (World Health Organization) (2008) Advocacy, Communication and Social Mobilization for TB Control: A Guide to Developing Knowledge, Attitude and Practice Surveys. Stop TB Partnership, Geneva. http://whqlibdoc.who.int/publications/2008/9789241596176 eng.pdf

[16] Haque, A., Haque, H.M., Hannan, A., Abdul Aziz, B., Nabilah, F., et al. (2019) Knowledge and Attitude Concerning Tuberculosis among the Employees of a Prison of Malaysia: A Cross-Sectional Study. International Journal of Pharmaceutical Research \& Allied Sciences, 7, 169-178.

[17] Ferreira Júnior, S., de Oliveira, H.B., Marin-Léon, L., Ferreira Júnior, S. and Marin-Léon, L. (2013) Knowledge, Attitudes and Practices on Tuberculosis in Prisons and Public Health Services. Revista Brasileira de Epidemiologia, 16, 100-113. https://doi.org/10.1590/S1415-790X2013000100010

[18] Nantha, Y.S. (2014) A Review of Tuberculosis Research in Malaysia. The Medical journal of Malaysia, 69, 88-102.

[19] Department of Statistics Malaysia Official Portal. https://www.dosm.gov.my/v1/index.php? $r=$ column/cthemeByCat\&cat=152\&bul id =NU5hZTRkOSs0RVZwRytTRE5zSitLUT09\&menu id=U3VPMldoYUxzVzFaYm NkWXZteGduZz09

[20] Abd Rahman, N.H. and Salwa Mokhtar, K. (2015) Challenges of National TB Control Program Implementation: The Malaysian Experience. Procedia-Social and Behavioral Sciences, 172, 578-584.

https://www.researchgate.net/publication/273501182 Challenges of National TB Control Program Implementation The Malaysian Experience

[21] Mehtar, S. (2008) Lowbury Lecture 2007: Infection Prevention and Control Strategies for Tuberculosis in Developing Countries-Lessons Learnt from Africa. The Journal of Hospital Infection, 69, 321-327. https://doi.org/10.1016/j.jhin.2008.04.015 
[22] Ministry of Health, Malaysia (2012) Guideline on Prevention and Management of Tuberculosis for Healthcare Workers in Ministry of Health, Malaysia.

[23] Tuberculosis I of M (US) C on ROE to, Field MJ (2001) Occupational Risk of Tuberculosis. National Academies Press, Washington DC.

https://www.ncbi.nlm.nih.gov/books/NBK222463/

[24] Jensen, P.A., Lambert, L.A., et al. (2005) Guidelines for Preventing the Transmission of Mycobacterium tuberculosis in Health-Care Settings. Morbidity and Mortality Weekly Report, 54, 1-141.

https://www.cdc.gov/mmwr/preview/mmwrhtml/rr5417a1.htm

[25] World Health Organization (2019) WHO Guidelines on Tuberculosis Infection Prevention and Control: 2019 Update.

http://www.ncbi.nlm.nih.gov/books/NBK539297/

[26] https://www.theunion.org/official-documents/AR2004 en.pdf

[27] Maher, D. (2003) Guidelines for Workplace TB Control Activities: The Contribution of Workplace TB Control Activities to TB Control in the Community. International Labour Organization, World Health Organization, Geneva.

http://books.google.com/books?id=VlNZAAAAYAAJ

[28] (2012) Malaysia, Kementerian Kesihatan, Bahagian Perkembangan Perubatan. Management of Tuberculosis.

[29] Malaysia Prisons Department. http://www.prison.gov.my/portal/page/portal/english/khidmat en

[30] Maher, D., Grzemska, M., Coninx, R. and Reyes, H. (1998) Guidelines for the Control of Tuberculosis in Prisons. 90.

[31] Scano, F., Cadman, H., Stop TB Initiative (World Health Organization), World Health Organization, HIV Department, World Health Organization, et al. (2009) WHO policy on TB Infection Control in Health-Care Facilities, Congregate Settings, and Households. http://www.ncbi.nlm.nih.gov/books/NBK179249/

[32] Correctional Facilities (2018) TB in Specific Populations. CDC. https://www.cdc.gov/tb/topic/populations/correctional/default.htm

[33] National Strategic Plan for Tuberculosis Control (2016-2020). 